\title{
Research and Practice of Performance Appraisal of Specialist Nursing Staff
}

\author{
Shuying Ling \\ The Fifth Affiliated Hospital of Guangzhou Medical University, Guangzhou 510700, Guangdong, China \\ Email: 673188907@qq.com
}

\begin{abstract}
The performance appraisal of specialist nurses is an important part of hospital human resource management, and it is also a necessary path to promote the professional development of specialist nurses. Based on the analysis and discussion of the framework design of the performance appraisal system for specialist nurses, this paper studies and discusses the design safeguard measures of the performance appraisal system for specialist nurses, in order to effectively improve the scientific performance of the specialist nurses' performance appraisal system. Level, lay a good foundation for the improvement of the professional nursing staff's work level and the sustainable development of the hospital.
\end{abstract}

Keywords: specialist nursing staff, performance appraisal

\section{Introduction}

In the human resource management of the hospital, the scientific and reasonable design and construction of the performance appraisal system for specialist nurses is not only conducive to reflecting the working level of specialist nurses and enhancing the enthusiasm of specialist nurses, but also can promote the professionalization of specialist nurses. On the basis of development, provide human resources support for the sustainable development of the hospital. It can be seen that the research and exploration of the performance appraisal system of specialist nursing staff has theoretical value and practical significance that cannot be ignored.

\section{Framework design of performance appraisal system for specialist nursing staff}

The performance appraisal system should fully embody the principle of distribution according to work, more work and more rewards, and good performance and rewards, and the distribution grades should be reasonably opened. This can improve the quality of nursing work and improve patients' satisfaction with nursing work ${ }^{[1]}$. Performance appraisal is an effective means in the process of performance management, and a reasonable salary distribution system is an important factor in retaining the backbone of the hospital and attracting medical talents ${ }^{[2]}$. In the process of constructing the performance appraisal system for professional nursing staff, the human resource management department needs to present the value orientation of promoting the professional development of specialist nursing staff, enhancing the enthusiasm of specialist nursing staff, promoting the sustainable development of the hospital, and demonstrating the public welfare of the hospital. Under this requirement, the performance appraisal framework for specialist nursing staff can be divided into four parts: fixed performance, job performance, operational performance and management performance.

From the perspective of fixed performance appraisal, the appraisal indicators included in the fixed performance appraisal mainly include the grade certificates, nursing grades, and professional titles held by specialist nursing staff. In the construction of the fixed performance evaluation index system, it is necessary for the evaluation subject to divide the different grade certificates into four groups A, B, C and D, and divide the fixed performance of nursing staff into a, b, c, and according to the nursing level and job title. $\mathrm{d}$ fourth gear. This approach can effectively encourage specialist nurses to obtain higher grade certificates, nursing levels and support, so as to give full play to the important role of specialist nurses' performance appraisal in promoting the professional development of appraisal targets and career development. In addition, in the process of fixed performance appraisal, it is necessary for the appraisal subject to examine the appraisal standards in the industry and the salary levels of different performance tiers. Only in this way can the fixed performance appraisal work be able to show higher levels both inside and outside the unit. Fairness and impartiality can also ensure that the fixed performance appraisal work can better play an incentive role.

From the perspective of work performance appraisal, work performance is mainly measured according to the department and workload of specialist nurses. Due to the obvious differences in the content and intensity of work faced by different positions, the development of this performance appraisal work needs to be established on the basis of 
scientific post analysis. It should be noted that although this performance appraisal content will cause the appraisal work to show differentiated characteristics due to job changes, this difference is more conducive to achieving fairness and justice, and promotes the performance appraisal of specialist nursing staff to show more work. The value orientation of gains, excellent performance and good remuneration, so as to ensure that the specialist nursing staff in each position can reflect a higher work enthusiasm in work practice, and further improve the work level. To this end, the human resource management department needs to make a scientific analysis of the positions of specialist nursing staff, and publicize the results of the job analysis and the work performance evaluation index system to ensure that the hospital staff can have a comprehensive understanding and high recognition of the relevant content., So as to lay a good foundation for the effective implementation of the differentiated work performance appraisal system.

From the perspective of operational performance appraisal, operational performance appraisal can reflect the controllable costs in the work process of specialist nursing staff. By carrying out this work, the performance appraisal subject can visualize the economic output value of specialist nursing staff. To understanding. Of course, many hospitals compare the operational performance of specialist nursing staff with the average operating performance of the hospital. Although this helps guide specialist nursing staff to pay more attention to creating economic benefits and promote the sustainable development of the hospital, it is in the assessment and evaluation Excessive emphasis on economic efficiency indicators will easily lead to the problem of specialist nurses in order to ensure that they obtain higher performance and salary levels, and pay attention to income generation but ignore innovation. In the long run, this situation will not only restrict the improvement of the hospital's social benefits, but also Affect the achievement of the hospital's economic efficiency goals. For this reason, it is necessary to take the balance between income generation and sustainable development as an important value orientation in the operational performance appraisal work. Under this guidance, if the floating performance is lower than the average performance of the hospital, it is determined by the hospital. The calculation of the average performance of the nurses ensures the protection of the specialist nurses, so that the specialist nurses can actively serve the clinic.

\section{Design safeguard measures for the performance appraisal system of specialist nursing staff}

The lack of a complete performance appraisal system will not only affect the quality of care, but also increase the incidence of adverse events, which is not conducive to the improvement of hospital brand effects ${ }^{[3]}$. In the process of reforming the performance appraisal system of specialist nurses, hospitals not only need to pay attention to guiding the participation of all staff, but also need to pay attention to improving the degree of understanding and recognition of the performance appraisal work of specialist nurses. At the same time, the design process of the performance appraisal system also needs to have complete organizational guarantees and resource guarantees, and comprehensively listen to the suggestions and opinions of specialist nursing staff in the design practice. Specifically, the hospital needs to do the following work.

First of all, the hospital management needs to increase the importance of the performance appraisal of specialist nursing staff, and pay attention to improving their own scientific management capabilities. The quality of outpatient care directly affects the overall service quality of patients to medical institutions and the degree of cooperation between patients and their families in follow-up treatment ${ }^{[4]}$. At the same time, nursing staff with greater work pressure are more likely to experience negative situations, and their work enthusiasm gradually decreases with the passage of working time, which has a negative impact on the quality of care ${ }^{[5]}$. For this reason, hospital management needs to pay attention to building a complete performance appraisal system. The "top leader" personally grasps it, which is of great significance to promote the effectiveness of the construction of the performance appraisal system for specialist nursing staff, and this not only puts forward higher requirements for the scientific management awareness of the "top leader", but also puts forward the scientific management of the "top leader". Management capabilities have brought higher challenges. Only by paying attention to improving the decision-making ability and leading ability of the "top leader" in the design and construction of the performance appraisal system of specialist nurses from the two levels of awareness and ability can we ensure that the performance appraisal work of specialist nurses can be effectively implemented from top to bottom, It can also give full play to the role of the specialty nursing staff performance appraisal system in promoting the professional development of specialty nursing staff and the sustainable development of the hospital.

Second, the hospital needs to provide organizational guarantees for the design of the performance appraisal system for specialist nursing staff. On the basis of the participation of "top leaders", it is necessary for the hospital to establish a design team for the performance appraisal system for specialized nursing staff. The construction of the team is mainly led 
by the human resources management department and the political engineering department. At the same time, the hospital party committee also needs to pay attention to the relevant work. Provide guidance and supervision. On this basis, team members also need to include personnel from the medical department, finance department, information department, quality control department and other units to ensure that each unit can achieve good collaboration in the design and implementation of the specialty nursing staff performance appraisal system. On the basis of ensuring that the design of the performance appraisal system for specialist nursing staff can be carried out effectively, it has laid a good foundation for its effective implementation.

Finally, hospitals need to pay attention to the application of the results of the performance appraisal of specialist nursing staff. Actively introducing an optimized performance appraisal management model can not only improve the work efficiency of nursing staff in all aspects, but also help improve patient satisfaction ${ }^{[6]}$. Paying attention to the performance appraisal process and ignoring the application of performance appraisal results will lead to a formal performance appraisal workflow. For this reason, on the one hand, the human resource management department needs to pay attention to the analysis of the implementation effect of the performance appraisal system and excavate the performance appraisal work. The existing problems provide a basis for the continuous optimization of the performance appraisal system. On the other hand, based on the design and implementation of the performance appraisal system, the human resource management department also needs to pay attention to the design of reward and punishment mechanism and incentive mechanism around the results of the performance appraisal, so as to promote the full play of the incentive role of the performance appraisal work.

\section{Conclusion}

In summary, the construction of a performance appraisal system for specialist nurses is of great significance to the professional development of specialist nurses and the sustainable development of hospitals. In the process of practice, the human resource management department needs to pay attention to the principle of fairness and justice in the fixed performance appraisal, work performance appraisal, and operational performance appraisal, reflecting the value orientation of taking into account economic and social benefits, and by increasing the degree of emphasis, providing organizations with Guarantee and attach importance to the application of performance appraisal results, and give full play to the value of the performance appraisal of specialist nursing staff.

\section{References}

[1] Feng Lihua, Ma Haiping, Xiu Huanjuan. Practice and effect of nursing staff performance appraisal reform. Qingdao Medicine and Health. 2020; 52(02): 110-112.

[2] Zhong Mingxia, Yang Huaiyu, Zhang Qiujun. The impact of the three-level public hospital performance appraisal system incentive mechanism on the nursing quality of hospital nurses under the background of the new medical reform. Journal of Practical Medical Technology. 2019; 26(10): 1347-1349.

[3] Li Zhen. The practice research of improving the performance appraisal system of outpatient nursing staff in outpatient management. Chinese Health Industry. 2019; 16(03): 103-104.

[4] Huang Boxia. The effect of improved performance appraisal system of outpatient nursing staff on nursing quality and overall satisfaction. Nursing Practice and Research. 2018; 15(22): 119-121.

[5] Zhang Fan, Wu Miaomiao. The impact of the performance appraisal joint reward and punishment system on the work enthusiasm and nursing quality of ICU medical staff. Journal of Traditional Chinese Medicine Management. 2018; 26(10): 73-74.

[6] Luo Lina. The impact of optimizing performance appraisal management on the effectiveness of surgical nursing staff. Chinese Health Industry. 2017; 14(35): 70-71. 